SJ Quinney College of Law, University of Utah Utah Law Digital Commons

Utah Law Faculty Scholarship

Utah Law Scholarship

2016

\title{
Role-play Simulations for Climate Change Adaptation Education and Engagement
}

Danya Rumore

S.J. Quinney College of Law, University of Utah, danya.rumore@law.utah.edu

Todd Schenk

School of Public and International Affairs Virginia Tech

Lawrence Susskind

Massachusetts Institute of Technology

Follow this and additional works at: http://dc.law.utah.edu/scholarship

Part of the Environmental Education Commons, Environmental Indicators and Impact Assessment Commons, and the Environmental Law Commons

\section{Recommended Citation}

Rumore, Danya; Schenk, Todd; and Susskind, Lawrence, "Role-play Simulations for Climate Change Adaptation Education and Engagement" (2016). Utah Law Faculty Scholarship. 30.

http://dc.law.utah.edu/scholarship/30 


\title{
Role-play simulations for climate change adaptation education and engagement
}

\author{
Danya Rumore, Research Assistant Professor* \\ Environmental Dispute Resolution Program, Wallace Stegner Center, S.J. Quinney \\ College of Law \\ City and Metropolitan Planning Department \\ University of Utah \\ 383 South University Street \\ Salt Lake City, Utah 84112 \\ danya.rumore@law.utah.edu \\ Todd Schenk, Assistant Professor \\ Urban Affairs and Planning, School of Public and International Affairs \\ Virginia Tech \\ 207 Architecture Annex (0113) \\ 140 Otey Street NW \\ Blacksburg, VA 24061 \\ tschenk@vt.edu
}

Lawrence Susskind, Ford Professor of Urban and Environmental Planning

Department of Urban Studies and Planning

Massachusetts Institute of Technology

9-332, 77 Massachusetts Ave.

Cambridge, MA 02139

susskind@mit.edu 


\begin{abstract}
In order to effectively adapt to climate change, public officials and other stakeholders need to rapidly enhance their understanding of local risks and ability to collaboratively and adaptively respond. We argue that science-based role-play simulation exercises, a type of 'serious game' involving face-to-face mock decision-making, have considerable potential as education and engagement tools for enhancing readiness to adapt. Prior research suggests role-play simulations and other serious games can foster public learning and encourage collective action in public policy-making contexts. However, the effectiveness of such exercises in the context of climate change adaptation education and engagement has heretofore been underexplored. We share results from two research projects that demonstrate the effectiveness of role-play simulations in cultivating climate change adaptation literacy, enhancing collaborative capacity, and facilitating social learning. Based on our findings, we suggest such exercises should be more widely embraced as part of adaptation professionals' education and engagement tool-kits.
\end{abstract}


Climate change poses serious threats to communities worldwide. While public officials in many towns and cities recognize the dangers they face, efforts to adapt are often limited by real and perceived uncertainty, capacity limitations, and competition among interests and priorities. For example, imagine the Town of Launton:

Over the past decade, the coastal New England community has been hit repeatedly by intense storms, which have caused significant damage to waterfront homes and business. Local officials are very concerned about the prospects for their small beachfront town, particularly since climate change projections indicate Launton will become increasingly vulnerable as the sea rises and more extreme storms occur. Unfortunately, they feel hamstrung by uncertainty about the nature and severity of climate change risks; already stretched resources; lack of public support for major investments and policy changes; and the absence of a clear roadmap for how to adapt to a changing climate.

Launton is a fabricated town in a role-play simulation (RPS) exercise designed for the Town of Wells, Maine - one of many RPSs being used to bring stakeholders together to learn about and discuss climate change adaptation. While Launton itself is imaginary, this scenario is all too real for many coastal towns and cities in the United States and elsewhere. Like Launton, many communities face widespread impacts from climate change, which - if not prepared for and effectively managed - could have devastating effects within the century. ${ }^{1}$ To help communities prepare for climate change risks, we need to find ways to enhance readiness to adapt.

There is a long history of using RPSs and other 'serious games' as education and engagement tools for tackling public policy challenges, including, increasingly, to advance climate change mitigation and adaptation action. ${ }^{2-7}$ While RPSs have been identified as particularly promising education and engagement tools for climate change adaptation, this potential had not been previously tested. We draw on the findings from 
our research to demonstrate that RPSs do indeed have considerable potential for helping stakeholders and communities adapt to climate change by educating them about climate change risks and building their capacity to collaboratively respond. Based on our findings, we conclude that RPSs should be more widely used as an adaptation education and engagement approach. We also discuss some of the limitations of this approach and lay out possible paths for future research and practice.

\section{The need to enhance readiness to adapt}

Stakeholders around the world are increasingly concerned about the need to prepare for and manage climate change impacts. ${ }^{8,9}$ Yet, despite this growing recognition and a continually improving technical understanding of climate-related risks, adaptation in practice remains limited. $^{10}$

The lack of adaptation action is by no means surprising. Preparing for and managing climate change risks is a collective risk management challenge. Stakeholders will have to work together over time to respond to risks as they emerge, despite differing ideas about the extent to which climate change is a problem and what if anything should be done about it. ${ }^{11}$ Adaptation is greatly complicated by a wide variety of challenges, ranging from scientific uncertainty, complexity, and limited resources to competing priorities and differences in risk perception. ${ }^{11-16}$ Such barriers underscore the need to consider underlying governance processes and socio-political concerns, rather than focusing on adaptation as solely a technical challenge. .,11 $^{8}$

Adaptation is further complicated by the fact that it is a 'wicked' planning problem: a problem with no clear problem definition, no stopping rule, and no clear or 
final solution. ${ }^{17}$ Adaptation is a moving target, requiring continuous learning, monitoring, adjustment, and renegotiation of objectives. ${ }^{11,18}$ Thus, effectively managing climate change risks will require a high level of 'response-ability,' or the ability to collectively respond to changing conditions as they emerge. ${ }^{19}$

Most communities - including municipalities, regions, nations, and organizations - are not ready to undertake the kinds of collective risk management that adaptation will require. ${ }^{11,18,20-22}$ This may explain why few communities have moved beyond the understanding phase of adaptation to the planning phase, and even fewer have moved on to implementation. ${ }^{16}$ Enhancing individual and collective readiness to prepare for and respond to climate change will require increasing literacy about climate change adaptation; people need to understand and accept climate-related risks and potential adaptation responses. Further, effectively responding to climate change risks will require coordination among diverse stakeholders within communities and across scales of governance in the face of uncertainty and complex science. Adaptation literacy must therefore be thought about at both the individual and community levels, and readiness to adapt will require a high level of collaborative capacity, or ability to work together to solve collective problems despite differing interests, perspectives, and areas of responsibility. ${ }^{11}$

To achieve these goals, stakeholders and communities need to develop a shared sense of the risks they collectively face, how they might prepare for and manage these risks, and the kinds of decision-making approaches that will allow them to respond collaboratively and adaptively to emerging threats. ${ }^{11,23}$ This, in turn, will demand a certain amount of social learning, a process by which stakeholders learn together and 
from each other to create a collective intelligence and shared understanding. ${ }^{24,25}$ It has been argued that, through generating shared understanding and a certain 'collaborative rationality,' social learning can lay the groundwork for stakeholders to reach agreement about shared issues and possible courses of action. ${ }^{26,27}$

Even if collective appreciation of risks and possible responses is achieved, stakeholders will still have to reconcile their interests to reach consensus on appropriate courses of action. Enhancing readiness to adapt, therefore, also requires that stakeholders understand the political realities that bound adaptation and that they find approaches for reconciling different interests in collective decision-making.

\section{Role-play simulations as a tool for adaptation education and engagement}

Serious games have gained attention as one way to advance climate adaptation action. ${ }^{28-}$

${ }^{31}$ A serious game is an exercise that directly engages participants in working to solve a realistic but fabricated challenge with the intent that they learn new material or approaches. ${ }^{32}$ Such games have been shown to be an effective for conveying complex information, teaching skills, and fostering mutual understanding and creativity in the public policy-making context. ${ }^{31,33-39}$ They can immerse people in realistic situations that they have not yet confronted; help them grapple first-hand with unprecedented and complex situations; and provide them with an opportunity to experiment in a safe, lowcost environment. ${ }^{29,31,40}$

For these reasons, it has been suggested in this journal and elsewhere that such exercises offer powerful tools for education and engagement. ${ }^{28,29}$ Accordingly, serious games are increasingly being used to educate the public about climate change and to 
prepare communities to participate in adaptation efforts. ${ }^{29,40-42}$ Yet, while strong statements about the usefulness of serious games in this context abound, very little research has rigorously tested the efficacy of such exercises against their intended learning and behavior change objectives, particularly at the group and community level.

Our work suggests that multi-stakeholder negotiation RPSs, a type of serious game, are particularly promising tools for education and engagement to advance climate adaptation action. In a RPS, participants are assigned individual roles and engage face-toface in a mock negotiated decision-making process that reflects real-world scientific information and institutional arrangements. RPSs have long been used in a variety of educational contexts where a sense of 'being there' is critical to understanding, including for emergency preparedness and negotiation training. ${ }^{43}$ They have all of the above-noted strengths of serious games. Additionally, they push participants to walk in someone else's shoes and to interact openly with different viewpoints, fostering what is called 'perspective taking,' or empathy for and understanding of different perspectives and interests. ${ }^{44}$ Such exercises can also be used to experientially introduce participants to new approaches for collective problem solving and planning, such as consensus building and scenario planning. ${ }^{11,23,40,42}$

Research suggests that RPSs can help participants learn technical and contentbased knowledge, such as the potential impacts of climate change, as well as processbased knowledge, such as how scientific uncertainty can influence decisionmaking. ${ }^{11,40,42,45}$ Multi-stakeholder negotiation RPSs also provide valuable 'safe spaces' for people to work through tough issues and learn together and from one another, including through post-exercise debriefings, which allow participants to collectively 
reflect on their shared experience and tie it back to real life. ${ }^{29,36,46}$ In light of these strengths, science-based RPSs show great potential as a tool for fostering climate adaptation literacy, enhancing collaborative capacity, facilitating social learning, and otherwise preparing stakeholders and the public to participate in the real collective risk management decisions facing their communities and organizations. ${ }^{11,23,42}$

\section{Using role-play simulations to advance adaptation action}

Recognizing this potential, we have been experimenting with RPSs as a way to help advance climate adaptation for almost a decade..$^{41,42,47-50}$ We provide all of our RPS participants with the same set of general instructions describing the context of the problem to be addressed during the exercise. Each individual is also given confidential role-specific instructions with information about the character s/he will play during the simulation. Participants then assume their assigned roles and engage in mock group decision-making for a set period of time. The period of game play is followed by a debriefing session, in which the full group of participants are brought together to reflect on and process the experience, and to explore how what they learned relates to their realworld situations.

The idea behind RPSs is to create a realistic but simplified setting in which participants can engage in group dialogue and negotiated decision-making, experiment with possible solutions, and learn to appreciate the perspectives of others - all while in a safe space. ${ }^{42}$ The game setting enables participants to deeply explore complex and often controversial issues and relationships, without direct political, financial, relational, or other consequences. ${ }^{11,27,42}$ 
The role-plays we construct do not promote any particular risk management strategy. On the contrary, they are designed to portray what is and is not known about climate risks and adaptation options, help participants engage with the potential costs and benefits of various adaptation strategies, and introduce a collaborative approach to adaptation decision-making. It is up to the participants to make their own determinations about what actions, if any, are appropriate for the scenario laid out in the simulation. The facilitated debriefing conversation after the simulation provides an opportunity for participants to make sense of their simulation experience and what they take away from it.

Our work with stakeholders grappling with climate change adaptation has consistently suggested that RPSs hold great promise for helping participants better understand the risks they face and devise collaborative approaches for addressing those risks. ${ }^{48-50}$ While the promise of the approach was clear, however, the effectiveness of RPSs as an adaptation education and engagement tool had heretofore not been rigorously tested. Recognizing this, we undertook two separate projects to systemically test the effectiveness of RPSs.

The Institutionalizing Uncertainty project engaged transportation infrastructure planners, decision-makers, and other stakeholders in the coastal cities of Rotterdam, Singapore, and Boston in exploring how they can effectively recognize and assess the dynamic and uncertain climate change risks they face, and how they can work together across traditional organizational, institutional, and interest-based boundaries to mitigate those risks. The goal was to advance our collective understanding of how complex and uncertain risks like climate change can best be handled, exploring questions of effective collaboration, the use of decision support tools (scenarios in particular), institutional 
change, and differences between governance regimes. An RPS was run with 76 participants across the three cities, placing them in a fictitious yet realistic situation in which they had to directly wrestle with whether and how to revise plans to construct a new highway in light of potentially significant, yet uncertain, climate risks. Participants completed pre- and post-exercise questionnaires, participated in a post-exercise debriefing, and were interviewed in the days following the exercise. The game play and debriefings were video recorded and coded for analysis.

The New England Climate Adaptation Project (NECAP) was a two-year participatory action research project that tested the effectiveness of RPSs as a public education and engagement tool, while simultaneously enhancing the readiness of four coastal New England communities to adapt to climate change. ${ }^{5,47}$ Project staff worked with local partners to develop a tailored RPS for each of the four municipalities. Each simulation was based on and included real-world downscaled climate change projections. The simulations also drew on the findings from in-depth interviews with local stakeholders, modeling realistic local political tensions. Over the course of six months, 110 to 170 people in each community were engaged in playing the simulation designed for their town. The project intentionally sought to engage local public officials in workshops with local residents to help generate shared understanding among the public and decision-makers. All NECAP workshop participants completed a questionnaire before and after the simulation and participated in debriefing conversations directly after the simulation. In-depth interviews were conducted with 20 to 30 percent of participants from each workshop 4 to 6 weeks after the event. Before- and after-workshop questionnaires were collected from a total of 510 participants. A total of 140 workshop 
participants participated in follow-up interviews. Quantitative and qualitative data collected were analyzed to evaluate the effect of the simulation workshops on individual and group perspectives about local risks and adaptation responses, the need for and importance of local action, confidence in the prospects of local action, and the importance of collective action and stakeholder engagement in adaptation planning.

For both projects, shifts in participants' perspectives were analyzed for statistical significance using the Wilcoxon matched pairs signed-rank test (see Supplementary Information).

\section{Evidence of the effectiveness of role-play simulations}

Our findings from these two projects provide strong evidence that participation in RPSs can increase readiness to adapt by cultivating literacy about climate change adaptation, enhancing collaborative capacity, and facilitating social learning. Furthermore, our findings suggest that when used as part of a broader engagement strategy, they can help catalyze climate change adaptation action.

\section{Cultivating adaptation literacy}

In NECAP we found that engagement in the RPSs resulted in a statistically significant increase in both participants' concern about local climate change risks ( $\mathrm{p}<0.05$; see Table 1 in Supplementary Information) and their sense that their town should take action to adapt ( $<<0.05$; see Table 2 in Supplementary Information). Many participants indicated that the simulation brought climate change risks and the need for collective adaptation action 'home' for them, helping them appreciate that climate change is a local issue and 
grasp how their town might be impacted. As one City of Dover resident explained in a representative quote, he had not realized "the vast amount of different areas that can be affected due to climate change." Moreover, he reported that the simulation showed him "how climate change can have such an effect on even a small place like Dover." Survey and interview findings from NECAP also show the exercise helped the majority of participants better understand the kinds of local actions that will be necessary to prepare for and respond to climate-related risks. Many participants noted that the simulation helped them understand that adaptation needs to be mainstreamed into everyday local planning, rather than done separately or on top of day-to-day decision-making.

The Institutionalizing Uncertainty project focused less on introducing substantive climate risks, but the findings were similar, with a statistically significant number of participants reporting increased awareness of climate change risks as a result of the exercise $(\mathrm{p}<0.05$; see Table 3 in Supplementary Information). Some emphasized the value of exercises as a delivery mechanism. In the words of a participant in Singapore: "Just telling people that climate change is important, they might not be convinced, but when they do a simulation, being in the role, actually [helps] them to appreciate the fact that climate change is [an] important considering factor."

Not surprisingly, in both projects the role-play simulations had the greatest detectable effect in terms of increased awareness and concern among those who had less knowledge or concern about climate change risks prior to the exercise. This suggests that RPSs are particularly useful for introducing climate adaptation to unfamiliar audiences and the 'undecided middle.' Based on the large dataset from NECAP, we also have reason to believe RPSs may be particularly effective for shifting opinions among those 
who are, to use the Yale Project on Climate Change Communication's Six Americas categorization, in the 'concerned' and 'cautious' categories in terms of their perspectives on climate change (see Table 4 in Supplementary Information). ${ }^{51}$

Our research also shows that RPSs can help stakeholders and community members better understand what will be involved in adapting to climate change and the challenges they are likely to face in doing so. In the Institutionalizing Uncertainty project, participation in the simulation resulted in a statistically significant increase in participants' perceptions of uncertainty as a complicating factor in adaptation planning $(\mathrm{p}<0.05$; see Table 5 in Supplementary Information). As one participant explained, "Before the game, I didn't think [uncertainty] was really that much of a problem because it was coming from my own point of view, and after the game, after interacting with the different people who have different agendas, different priorities, I realized how, when those come together, the uncertainty can increase." Reflecting on what they learned, participants were surprised to find that many of the significant challenges and sources of uncertainty inhibiting effective adaptation are not scientific, but rather governance issues that require robust institutional responses.

Along similar lines, the strong majority of NECAP participants showed signs of significantly enriched understanding about the complexity of climate change and what adaptation will entail. As a Town of Wells interviewee remarked while reflecting on the simulation, "Even though I think of myself as knowledgeable about the basics of climate change, I hadn't really considered the process of actual decision-making in communities and figuring out what to do." A city councilwoman and coastal property owner in the City of Cranston said of the simulation, "it helped me prioritize and see the whole picture 
of what the city is grappling with."

The RPSs not only increased participants' understanding of and concern about climate change risks, they also increased their confidence in the prospects of adaptation action. In NECAP, there was a statistically significant increase in participants' confidence that their town could take meaningful adaptation action $(\mathrm{p}<0.05$; see Table 6 in Supplementary Information). Participants attributed their increased confidence to the fact that the simulation demonstrated pathways their town might take to adapt and helped them realize that others in their community, including public officials, are taking the issue seriously. However, among the participants who entered the NECAP workshops already very confident their town could effectively adapt, the simulation actually led to, on average, a modest decrease in confidence. These participants noted that the simulation made them realize how truly challenging climate change adaptation will be.

Among Institutionalizing Uncertainty participants, there was also a statistically significant increase in confidence that they and their counterparts in other organizations can successfully adapt ( $<<0.05$; see Table 7 in Supplementary Information). Like the NECAP participants, however, some felt less confident and many stayed the same. Participants whose confidence decreased as a result of the exercise cited barriers to adaptation - including deficient professional capacity, inflexible institutional norms and standards, and persistent uncertainty (which the exercise highlighted) - as the reason for their increased skepticism. 


\section{Enhancing collaborative capacity}

Our results also suggest that RPSs can help lay the foundation for collaborative risk management by highlighting the interdependency of stakeholders, increasing empathy for different perspectives, building support for collaborative decision-making, and introducing complementary tools and approaches.

In the Institutionalizing Uncertainty project, participants were asked both before and after the exercise how important it is that they engage with other decision-makers and stakeholders as they plan and make decisions about adaptation. Following participation in the RPS, there was a statistically significant increase in the perceived importance of engaging diverse stakeholders in adaptation decision-making $(p<0.05$; see Table 8 in Supplementary Information). The importance of broad engagement was universal across the three cities, although there was notable variation in opinions about who should be engaged, which seemed to directly reflect cultural norms about governance. In Boston, non-governmental actors are playing key roles in the region's nascent adaptation efforts and participants praised their prominence. In contrast, participants in Singapore agreed on the importance of cross-governmental collaboration, but many were wary of extensively involving external stakeholders.

Participation in the NECAP simulations also resulted in a notable increase in participants' sense of how important it is to engage diverse stakeholders in adaptation decision-making. As one participant explained, "The workshop made me more aware of the fact that more citizens - all citizens - should be taking a look at what's going on and taking a role in it." 
In addition to increasing participants' belief in the importance of engaging diverse stakeholders in adaptation decision-making, the RPSs increased participants' understanding of and empathy for diverse perspectives. More than half of NECAP interviewees showed significant signs of increased empathy and appreciation for other viewpoints as a result of their participation in the exercise. Interview findings suggest there were two main reasons for this. First, the simulation pushed participants to take on another role and engage with issues from a different perspective. Second, the simulation created a safe space for participants to openly engage with other stakeholders' viewpoints. People commonly said it was very eye opening to 'walk in someone else's shoes.' As one workshop participant said of his experience in a comment that was reflective of sentiments expressed by others: "You had to sit down and say: maybe this guy has a point. I never thought about it."

The findings were similar in the Institutionalizing Uncertainty project. "One thing I find very useful about this gaming exercise is that you force participants to put on different hats, and so they put themselves in the shoes of that role, and that helps to get them out of their own comfort zone, the role that they are playing in office," said a participant in Singapore, reflecting broadly-held sentiments. She added, "They are [subsequently] able to see the other side of the argument, the other argument, the counterarguments, and that $[\ldots]$ sensitizes them to certain issues. And when they return to their portfolio, they are better able to formulate plans or strategies for that particular issue. So it broadens their perspective."

The simulations also appear to have effectively introduced the merits of more collaborative approaches to decision-making. After participating in the RPS, $72 \%$ of 
NECAP participants expressed support for their town undertaking a consensus buildingtype approach to adaptation decision-making, like that modeled in the simulation (see Figure 1 in Supplementary Information). Institutionalizing Uncertainty participants also voiced high levels of support for a consensus building approach to adaptation decisionmaking following the RPS. As one participant lamented: "I wish that the approach to decision-making were more like that [followed in the exercise] in the real world; ultimately, decisions are made somewhat mysteriously, and I don't think that they are made so openly as part of [this type of] consensus building group".

The exercises also effectively introduced methods by which multi-stakeholder groups might deliberate and engage effectively in productive dialogue. Institutionalizing Uncertainty participants reported that they learned about the importance of a welldesigned and facilitated decision-making process, especially when tackling complex challenges like climate adaptation. They also indicated that the experience underscored the impact stakeholder interactions and negotiation skills can have on the outcomes; those that were adept at seeking mutual gains and/or arguing their cases were more successful in getting what they wanted. In general, participants reflected that this kind of process is enhanced by good deliberative technique.

\section{Fostering social learning}

Our experience with NECAP strongly suggests that engaging diverse groups of stakeholders through RPSs creates a powerful forum for social learning. NECAP participants commonly reflected on the fact that the simulations created a safe space and a valuable opportunity for bringing local decision-makers and other diverse community 
members together to talk about local climate change risks. They suggested this community learning was a powerful influence on their perspectives. In the words of one Town of Wells interviewee, it is "nice to know that I'm not alone in this, that there are others who also want to keep things happening." A City of Dover resident said of the experience, "it gave me some confidence that the city officials and citizens were really trying to engage in this" and "gave me some hope that Dover... can actually do some good planning."

Similarly, many participants and project partners felt that the simulation workshops were a critical conversation starter for their communities, helping people to, as one project partner put it, 'leapfrog' over the typical debate about whether climate change is happening to instead focus on what the town could do to prepare for and respond to climate-related risks. In the words of a Town of Barnstable participant, "It forces the communication to happen... If we sat down there without the role-playing, some ideas are thrown out there. But when we're doing that role-playing, whether you agree with it or not, it forces the subject matter to be put on the table. And it works."

The impacts of this social learning on adaptation action will take time to fully manifest and are hard to measure. However, there are strong initial signs from NECAP that this learning is translating into community decision-making. All four NECAP partner municipalities are beginning to integrate the climate change projections developed through the project into their planning and zoning updates, and many of the communities have pursued federal and other funding to enable them to do more in-depth vulnerability studies. Perhaps most importantly, climate change risks are now on the political docket in a way they definitely were not before the project. As a City of Cranston public official 
put it, the project had the effect of getting public officials "outside their comfort zones and talking about adaptation planning as a normal part of their duties - [that] wouldn't have happened without this project." Another project partner said the simulations "helped build dialogue that may have never happened without this project." These effects must be understood as resulting from the broader NECAP effort and not just the role-play simulation workshops. However, they provide further evidence that social learning has occurred in these communities, and speak to the potential of RPSs to act as inflection points for broader adaptation education and engagement strategies. ${ }^{11}$

\section{Adding role-play simulations to the adaptation tool-kit}

The NECAP and Institutionalizing Uncertainty projects provide rigorous empirical evidence that science-based role-play simulations can indeed be powerful tools for stakeholder education and engagement around climate change adaptation. They give us reason to believe such exercises can help stakeholders understand climate change risks and build support for adaptation action, enrich participants' understanding of what climate change adaptation will entail and the challenges it will present, and increase support for collaboratively engaging diverse stakeholders in adaptation decision-making. Further, the NECAP experience demonstrates that such exercises, when nested in broader engagement processes, can serve as valuable conversation starters, fostering social learning and potentially acting as catalysts for action. In light of these findings, we feel confident that RPSs are a valuable addition to adaptation professionals' tool-kits, and we encourage others to experiment with them as an approach to adaptation education and engagement. 
In considering the potential of these exercises as adaptation support tools, a number of caveats and limitations need to be acknowledged. First, RPSs are conversation starters. They are not meant to stand-alone, but rather to be used as part of wider engagement strategies and adaptation planning initiatives. They can help participants build foundations for actual decision-making and introduce options, but are oversimplifications of reality and are not intended to help participants arrive at the real-world answers. This is one reason why debriefing conversations following RPSs are so important; facilitated post-exercise dialogue allows participants to make sense of their simulation experience and tie their learning back to reality.

Secondly, we have found that tailoring exercises to specific contexts, as in the case of the simulations discussed here, is preferable. However, this requires substantial skill, resources, and time. Where tailoring RPSs to specific contexts is not feasible, existing games can be used or modified to kick off important conversations.

Finally, a common concern with using RPSs for stakeholder engagement is that it can be difficult to get people to participate. While it is true that busy public officials may not want to 'waste time playing a game' and the general public may be skeptical, we have found that participants almost always enjoy the experience and, in retrospect, say they found it valuable. Referring to an exercise as a 'simulation' rather than a 'game' may make it more appealing for professional crowds, and many participants find the prospects of engaging in an experiential learning exercise more attractive than simply attending a town hall or public meeting.

It is also important to note that the generalizability of these findings to other types of serious games is unclear. Our experience suggests that the face-to-face element of 
RPSs is key to the value they provide, although this hypothesis has not been verified. The efficacy of different kinds of serious games for social learning and engagement around adaptation merits further rigorous study.

The potential to build on the paper-based RPS model described here by integrating different technologies, such as computer game engines that provide feedback on the impacts of different decisions, ${ }^{52,53}$ merits further exploration and empirical study. Additional research is also needed to examine the extent to which RPSs are effective across different cultures and contexts. Finally, there is considerable potential to use RPSs as a research tool, such as to understand institutional and group dynamics in the context of making adaptation decisions. The Institutionalizing Uncertainty project hints at their value in this respect, but more work is needed to clarify what we can and cannot learn by observing play and what other research methods can be paired with RPSs to generate information relevant to adaptation policy-making.

The seriousness of climate change and the urgent need for adaptation require that we become creative in our approaches to fostering support for action and building the capacity of stakeholders to effectively respond. Adapting to climate change is no game, but we have reason to believe role-play games can help. 


\section{References}

1. IPCC. in Clim. Chang. 2014 Impacts, Adapt. Vulnerability. Part A. Glob. Sect. Asp. Contrib. Work. Gr. II to Fifth Assess. Rep. Intergov. Panel Clim. Chang. (Field, C. et al.) (Cambridge University Press, 2014).

2. Geurts, J. L. A., Duke, R. . \& Vermeulen, P. A. M. Policy gaming for strategy and change. Long Range Plann. 40, 535-558 (2007).

3. Brewer, G. D. Scientific gaming: The development and use of free-form scenarios. Simul. Gaming 9, 309-338 (1978).

4. Haug, C., Hujtema, D. \& Wenzler, I. Learning through games? Evaluating the learning effect of a policy exercise on European climate policy. Technol. Forecast. Soc. Change 78, 968-981 (2011).

5. Mayer, I. S. The Gaming of Policy and the Politics of Gaming: A Review. Simul. Gaming 40, 825-862 (2009).

6. Mayer, I. et al. The research and evaluation of serious games: Toward a comprehensive methodology. Br. J. Educ. Technol. 45, 502-527 (2014).

7. Parson, E. A. Informing global environmental policy-making: A plea for new methods of assessment and synthesis. Environ. Model. Assess. 2, 267-279 (1997).

8. Birkmann, J., Garschagen, M., Kraas, F. \& Nguyen, Q. Adaptive urban governance: New challenges for the second generation of urban adaptation strategies to climate change. Sustain. Sci. 5, 185-206 (2010).

9. Hallegatte, S., Green, C., Nicholls, R. J. \& Corfee-Morlot, J. Future flood losses in major coastal cities. Nat. Clim. Chang. 3, 802-806 (2013).

10. Lemos, M. C., Kirchhoff, C. J. \& Ramprasad, V. Narrowing the climate information usability gap. Nat. Clim. Chang. 2, 789-794 (2012).

11. Susskind, L., Rumore, D., Hulet, C. \& Field, P. Managing Climate Change Risks in Coastal Communities: Strategies for Engagement, Readiness, and Adaptation. (Anthem Press, 2015).

12. Amundsen, H., Berglund, F. \& Westskog, H. Overcoming barriers to climate change adaptation - a question of multilevel governance? Environ. Plan. C Gov. Policy 28, 276-289 (2010).

13. Anguelovski, I. \& Carmin, J. Something borrowed, everything new: innovation and institutionalization in urban climate governance. Curr. Opin. Environ. Sustain. 3, 169-175 (2011).

14. Biesbroek, R., Klostermann, J., Termeer, C. \& Kabat, P. Barriers to climate change adaptation in the Netherlands. Clim. Law 2, 181-199 (2011).

15. Measham, T. G. et al. Adapting to climate change through local municipal planning: Barriers and challenges. Mitig. Adapt. Strat. Glob. Chang. 16, 889-909 (2011).

16. Moser, S. C. \& Ekstrom, J. A. A framework to diagnose barriers to climate change 
adaptation. Proc. Natl. Acad. Sci. U. S. A. 107, 22026-22031 (2010).

17. Rittel, H. \& Webber, M. Dilemmas in a General Theory of Planning. Policy Sci. 4, 155-169 (1973).

18. Moser, S. C. \& Boykoff, M. T. in Success. Adapt. to Clim. Chang. Link. Sci. Policy Rapdly Chang. World (Moser, S. C. \& Boykoff, M. T.) 1-34 (Routledge, 2013).

19. Collins, K. \& Ison, R. Jumping off Arnstein's ladder: Social learning as a new policy paradigm for climate change adaptation. Environ. Policy Gov. 19, 358-373 (2009).

20. Adger, W. N. et al. in Clim. Chang. 2007 Impacts, Adapt. Vulnerability. Contrib. Work. Gr. II to Fourth Assess. Rep. Intergov. Panel Clim. Chang. (Parry, M. L., Canziani, O. F., Palutikof, J. P., van der Linden, P. J. \& Hanson, C. E.) 717-743 (Cambridge University Press, 2007). at $<\mathrm{http}: / /$ www.resalliance.org/index.php?id=9835\&sr=1>

21. Ford, J. D., Berrang-Ford, L. \& Paterson, J. A systematic review of observed climate change adaptation in developed nations. Clim. Change 106, 327-336 (2011).

22. NRC (National Research Council). Adapting to the Impacts of Climate Change. (2010).

23. Susskind, L. Responding to the risks posed by climate change: Cities have no choice but to adapt. Town Plan. Rev. 81, 217-235 (2010).

24. Reed, M. et al. What is social learning? Ecol. Soc. 15, (2010).

25. Pahl-Wostl, C. \& Hare, M. Processes of social learning in integrated resources management. J. Community Appl. Soc. Psychol. 206, 193-206 (2004).

26. Innes, J. \& Booher, D. Planning with complexity: an introduction to collaborative rationality for public policy. (Random House, 2010).

27. Innes, J. \& Booher, D. Consensus building as role playing and bricolage: Toward a theory of collaborative planning. J. Am. Plan. Assoc. 65, 9-26 (1999).

28. Wu, J. S. \& Lee, J. J. Climate change games as tools for education and engagement. Nat. Clim. Chang. 5, 413-418 (2015).

29. Mendler de Suarez, J. et al. Games for a New Climate: Experiencing the Complexity of Future Risks. Pardee Center Task Force Report. . (The Frederick S. Pardee Center for the Study of the Longer-Range Future, Boston University, 2012).

30. NRC (National Research Council). Informing an Effective Response to Climate Change Informing an Effective Response to Climate Change. (2010).

31. Jones, L., Ludi, E., Beautement, P., Broenner, C. \& Bachofen, C. New approaches to promote flexible and forward-looking decision making: Insights from complexity science, climate change adaptation and 'serious gaming'. (2013).

32. Abt, C. C. Serious Games. (University Press of America, 2002). 
33. Dolin, E. J. \& Susskind, L. E. A Role for Simulations in Public Policy Disputes: The Case of National Energy Policy. Simul. Gaming 23, 20-44 (1992).

34. Parson, E. A. in Wise Choices Decis. Games, Negot. (Zeckhauser, R. J., Keeney, R. L. \& Sebenius, J. K.) (Harvard Business School Press, 1996).

35. DeNeve, K. M. \& Heppner, M. J. Role play simulations: The assessment of an active learning technique and comparisons with traditional lectures. Innov. High. Educ. 21, 231-246

36. Susskind, L. \& Corburn, J. Using Simulations to Teach Negotiation : Pedagogical Theory and Practice. (1999).

37. Najam, A. Getting Beyond the Lowest Common Demonimator: Developing Countries in Global Environmental Negotiations. (2001).

38. Mayer, I. S. The Gaming of Policy and the Politics of Gaming: A Review. Simul. Gaming 40, 825-862 (2009).

39. Grüne-Yanoff, T. \& Weirich, P. The Philosophy and Epistemology of Simulation: A Review. Simul. Gaming 41, 20-50 (2010).

40. Schenk, T. \& Susskind, L. in Action Res. Adapt. Pract. Dev. Appl. Knowl. Gov. (Buuren, A. van \& Vliet, M. van) (Routledge, 2014).

41. Susskind, L. \& Rumore, D. Collective Climate Adaptation : Can Games Make a Difference? Solut. J. 4, 5-9 (2013).

42. Schenk, T. in Infranomics Sustain. Eng. Des. Gov. (Gheorghe, A. V, Masera, M. \& Katina, P. F.) (Springer, 2014).

43. Gordon, E., Schirra, S. \& Hollander, J. Immersive planning: a conceptual model for designing public participation with new technologies. Environ. Plan. B Plan. Des. 38, 505-519 (2011).

44. Yee, N. \& Bailenson, J. Walk a mile in digital shoes: The impact of embodied perspective-taking on the reduction of negative stereotyping in immersive virtual environments. in PRESENCE 2006 9th Annu. Int. Work. Presence (2006).

45. Stokes, L. C. \& Selin, N. E. The mercury game: evaluating a negotiation simulation that teaches students about science-policy interactions. J. Environ. Stud. Sci. (2014). doi:10.1007/s 13412-014-0183-y

46. Crookall, D. Serious Games, Debriefing, and Simulation/Gaming as a Discipline. Simul. Gaming 41, 898-920 (2011).

47. Rumore, D. Building the Capacity of Coastal Communities to Adapt to Climate Change through Participatory Action Research : Lessons Learned from the New England Climate Adaptation Project. Carolina Plan. J. 39, 16-23 (2014).

48. Susskind, L. \& Paul, E. Winning Public Support for Addressing Climate Change. Solut. J. 1, 44-48 (2010).

49. United Nations Development Programme \& World Bank. World Resources Report 2010-2011: Decision Making in a Changing Climate - Adaptation Challenges and Choices. (World Resources Institute, 2011). 
50. Rumore, D. An exploratory investigation of the use of role-play simulations as a tool for helping communities plan and prepare for climate change adaptation. (2012).

51. Leiserowitz, A., Maibach, E. W., Roser-Renouf, C. \& Smith, N. Global Warming's Six Americas, May 2011. (Yale Project on Climate Change Communication, 2011). at $<$ http://sciencepolicy.colorado.edu/students/envs3100/maibach2011.pdf $>$

52. Tygron. Next Generation Planner. (2016). at $<$ http://www.tygron.com $>$

53. Poplin, A. Digital serious game for urban planning: 'B3 - Design your Marketplace!' Environ. Plan. B Plan. Des. 41, (2014).

\section{Corresponding author}

Correspondence and requests for materials should be addressed to Danya Rumore (Danya.rumore@law.utah.edu)

\section{Acknowledgements}

The New England Climate Adaptation Project was supported with funding from the University of New Hampshire and the National Oceanic and Atmospheric Administration under Cooperative Agreement No. NA09NOS4190153 (CFDA No. 11.419). The Institutionalizing Uncertainty project received support from the Dutch Knowledge for Climate Program, funded through TNO; the Program on Negotiation at Harvard Law School; and the Tufts-MIT Water Diplomacy Program. The authors also wish to acknowledge all of the NECAP research team members, partners, and workshop participants who made the project possible, as well as Ellen Czaika for her help in statistically analyzing NECAP data. They also wish to thank the incredible local partners and participants in the three case cities in the Institutionalizing Uncertainty project, and 
in particular project partners at TNO.

\section{Author contributions}

D.R. conceptualized the research questions and analyzed data for NECAP. T.S. conceptualized the research questions and analyzed data for Institutionalizing Uncertainty. L.S. provided mentoring and oversight for both projects. D.R. and T.S. contributed equally to the preparation of this manuscript, with input from L.S. 